Correspondence

J. G. Coote

j.coote@bio.gla.ac.uk

Received 19 December 2006 Accepted 26 February 2007

\section{Comparison of virulence-associated in vitro properties of typed strains of Campylobacter jejuni from different sources}

\author{
J. G. Coote, ${ }^{1}$ D. E. S. Stewart-Tull, ${ }^{1}$ R. J. Owen, ${ }^{2}$ F. J. Bolton, ${ }^{3}$
} Berit L. Siemer, ${ }^{4}$ Denise Candlish, ${ }^{1}$ D. H. Thompson, ${ }^{5}$ A. C. Wardlaw, ${ }^{1}$ S. L. W. On, ${ }^{4}$ A. Candlish, ${ }^{1}$ Bronwen Billcliffe, ${ }^{1}$ Penelope J. Jordan, ${ }^{4}$ K. Kristiansen ${ }^{4}$ and Pauline Borman ${ }^{2}$

${ }^{1}$ Division of Infection and Immunity, Institute of Biomedical and Life Sciences, Glasgow Biomedical Research Centre, University of Glasgow, Glasgow G12 8TA, UK

${ }^{2}$ Centre for Infections, Health Protection Agency Colindale, 61 Colindale Avenue, London NW9 5HT, UK

${ }^{3}$ Royal Preston Hospital, Public Health Laboratory, PO Box 202, Sharoe Green Lane North, Lancashire PR2 9HG, UK

${ }^{4}$ Danish Institute for Food and Veterinary Research, Department of Microbial Food Safety, Bulowsvej 27, DK-1790 Copenhagen V, Denmark

${ }^{5}$ Department of Veterinary Pathology, Veterinary School, University of Glasgow, Garscube Estate, Bearsden, Glasgow G61 10H, UK

Campylobacter jejuni is a major cause of human diarrhoeal disease, but specific virulence mechanisms have not been well defined. This blinded study was undertaken with $40 \mathrm{C}$. jejuni isolates from different sources to determine their haemolytic, cytotoxic and adhesion and invasion activities towards mammalian cells. The results were correlated with source of isolation and genetic makeup by amplified fragment length polymorphism (AFLP) typing. The isolates had variable degrees of haemolytic activity against rabbit erythrocytes and cytotoxicity towards $\mathrm{CaCo}^{-}$ 2, HeLa and Vero cells. The data indicated that the haemolytic and cytotoxic activities were due to separate factors. A range of cytotoxicity was exhibited, whereby some strains had no activity against the target cells and others had activity against all three cell lines. Certain strains had activity against $\mathrm{CaCo}-2$ cells but little or no activity against the other cells, while others exhibited the opposite phenotype. The data suggested that the cytotoxicity assay with the different cell lines may have detected more than one cytotoxin. A wide variation between isolates was observed for both adherence and invasion with all three cell lines, yet, overall, the strains showed a significantly greater invasion capacity for $\mathrm{CaCo}-2$. There was no clear relationship between source of isolation or disease manifestation and possession of statistically significantly higher levels of particular virulence-associated factors although, in some cases, a correlation between cytotoxicity and cell invasion was evident. Five AFLP clusters, each representing two to eleven isolates with similar profiles, were observed at the $90 \%$ similarity level. Some AFLP groups contained isolates with a common serotype, but each group had C. jejuni isolates from more than one source with the exception of group IV, which contained only human isolates. Isolates with high cytotoxic activity against $\mathrm{CaCo}-2$ cells were confined to groups I, III and IV and a group of unrelated strains (U). Group II isolates had uniformly low cytotoxicity. Isolates in groups I, V and U were more invasive for CaCo-2 cells than isolates in groups II, III and IV. The strain differences in cytotoxicity or invasion did not correlate with source of isolation. 


\section{INTRODUCTION}

Campylobacter jejuni is a major cause of human enteritis and diarrhoeal disease. Virulence mechanisms have been attributed to motility, adherence, cytotoxin and enterotoxin production and invasion of the gut mucosa (Griffiths \& Park, 1990; Ketley, 1997; Wassenaar \& Blaser, 1999). However, which determinant(s) plays the major role in perturbation of the normal absorptive capacity of the intestinal epithelium that causes the transient watery diarrhoea, and/or blood and leukocytes sometimes found in stools, is still unclear. The disease features could also be attributed to an inflammatory response (Everest et al., 1993; Hickey et al., 1999; Mellits et al., 2002; MacCallum et al., 2005). Campylobacters enter the host by the oral route and colonize the distal ileum and colon. Adhesion to the epithelial cell layer (Konkel \& Joens, 1989; Konkel et al., 1992) can be followed by invasion of epithelial cells, but this has been reported to be strain-dependent, since some strains adhered to tissue culture cells without invasion, while the capacity of others for invasion was $10^{2}-10^{4}$ times higher (Everest et al., 1992; Oelschlaeger et al., 1993). A significant correlation was reported between invasive ability and the presence of colitis in patients from which isolates were obtained (Everest et al., 1992).

Haemolysin activity has been reported from several laboratories, including our own study (Hossain et al., 1993), but whether this factor is related to other reported cytotoxic activities is not known. Low-level cytotoxic activity of $C$. jejuni culture filtrates or polymyxin Breleased cell extracts affecting the integrity of mammalian cells has been assayed by the cytopathic changes in cultured cells, but this has produced only semiquantitative data (Wassenaar, 1997; Pickett, 2000). In a previous report, the cytotoxic activity of cell extracts and culture supernates from four C. jejuni strains was assayed against HeLa and Vero cells with a quantitative dye-reduction assay (Coote $\&$ Arain, 1996). Here, a blinded study of the haemolytic and cytotoxic activities, adhesion and invasion properties and amplified fragment length polymorphism (AFLP) typing of 40 C. jejuni isolates from different sources is reported, in an attempt to correlate laboratory activities towards mammalian cells, which arguably might be involved in pathogenicity, with genetic makeup and source of isolation.

\section{METHODS}

Bacterial strains and growth conditions. Thirty coded $C$. jejuni isolates were provided by one of us (R. J. O.) and designated COL 130. COL 7 was the type strain NCTC $11168^{\mathrm{T}}$. Ten coded C. jejuni isolates were provided by another of us (F.J.B.) and designated RPH1-10 (Table 1). These isolates were serotyped (Penner \& Hennessy, 1980; Owen et al., 1995) and ribotyped (Fitzgerald et al., 1996). The source of the isolates is included in Table 1. The C. jejuni isolates were subcultured on blood agar base (Oxoid) supplemented with $5 \%(\mathrm{v} / \mathrm{v})$ defibrinated sheep blood (Gibco) and Blaser-Wang selective supplement (Oxoid) and incubated at $42{ }^{\circ} \mathrm{C}$ in anaerobic jars under a gas atmosphere of $5 \% \mathrm{O}_{2}, 15 \% \mathrm{CO}_{2}$ and $80 \% \mathrm{~N}_{2}$ (BOC). The isolates were identified by standard tests including colonial morphology, Gram stain, motility, positive oxidase and catalase tests, lack of growth at $25{ }^{\circ} \mathrm{C}$ and positive hippurate test (Ullmann, 1979). After primary isolation, the isolates were subcultured only once to minimize cultural changes, after which samples of each, stored at $-70{ }^{\circ} \mathrm{C}$ in Brucella broth (Oxoid) and glycerol $(60: 40 \mathrm{v} / \mathrm{v})$, were used for a limit of five subcultures before a new stored culture was used. For growth in liquid medium, a loopful of the C. jejuni growth on agar medium was inoculated into $100 \mathrm{ml}$ Brucella broth and incubated in an anaerobic jar, under the same microaerophilic atmosphere as above, at $42{ }^{\circ} \mathrm{C}$ in an orbital shaker at 100 r.p.m.

Haemolysis assay. C. jejuni isolates were grown in Brucella broth as described above for $48 \mathrm{~h}$, after which time the cells were centrifuged at $1500 \mathrm{~g}$ for $20 \mathrm{~min}$ at $4{ }^{\circ} \mathrm{C}$ and then resuspended to an $\mathrm{OD}_{650}$ of 2.0 in PBS, and $50 \mu$ of doubling dilutions of the cell suspension added to $50 \mu \mathrm{l}$ PBS was distributed into the wells of 96-well microtitre plates. To each well was added $100 \mu \mathrm{l}$ freshly collected rabbit red blood cells (RRBC), washed three times in PBS and resuspended to a concentration of $1 \%(\mathrm{v} / \mathrm{v})$ in PBS. The mixture was incubated at $42{ }^{\circ} \mathrm{C}$ for $2 \mathrm{~h}$. The plates were centrifuged at $1500 \mathrm{~g}$ for $10 \mathrm{~min}$ and $100 \mu \mathrm{l}$ supernate was removed from each well and the $A_{540}$ was measured in an Anthos 2001 microplate reader. RRBCs lysed with $1 \%$ $(\mathrm{v} / \mathrm{v})$ Triton X-100 served as a positive control and an RRBC suspension with PBS alone was used as a negative control. Results were expressed as the reciprocal of the highest dilution that produced $50 \%$ haemolysis.

Preparation of $\boldsymbol{C}$. jejuni extracts for cytotoxin assays. Broth cultures, prepared as described above, were centrifuged at $1500 \mathrm{~g}$ for $20 \mathrm{~min}$ at $4{ }^{\circ} \mathrm{C}$. The cell pellets were resuspended to an $\mathrm{OD}_{650}$ of 2.0 in PBS containing $0.15 \%(\mathrm{w} / \mathrm{v})$ polymyxin B (Sigma) to promote the release of cell-associated material. Polymyxin was used previously to demonstrate cytotoxin production by C. jejuni (Guerrant et al., 1987). After incubation at $37{ }^{\circ} \mathrm{C}$ for $30 \mathrm{~min}, 1.0 \mathrm{ml}$ of the treated cells was centrifuged at $2500 \mathrm{~g}$ for $20 \mathrm{~min}$ and the supernates were passed through a $0.45 \mu \mathrm{m}$ filter (Acrodisc; Gelman Sciences); the filtrates were stored at $-20{ }^{\circ} \mathrm{C}$ until required. Each isolate was tested in duplicate at least three times on separate occasions in the cytotoxicity assay.

Preparation of mammalian cell suspensions. HeLa (human epithelial cervical carcinoma) and Vero (African green monkey kidney) cells (Flow Laboratories) were propagated as monolayers within plastic tissue-culture flasks in Eagle's minimal essential medium (E-MEM; Flow Laboratories) supplemented with $2 \mathrm{mM} \mathrm{L}-$ glutamine and $10 \%(\mathrm{v} / \mathrm{v})$ fetal calf serum (both from Flow Laboratories). Penicillin and streptomycin (both at $100 \mathrm{IU} \mathrm{ml}^{-1}$; Sigma) were added to prevent bacterial contamination. Cell monolayers were detached by the addition of a trypsinizing solution [0.05\% (w/v) trypsin, $0.02 \%(w / v)$ EDTA; Flow Laboratories] and gentle tapping of the flask. Cell aggregates in the suspension were dispersed by sterile-pipetting before the cells were washed in fresh medium and suspended to a final viable cell density of $5 \times 10^{4}$ cells $\mathrm{ml}^{-1}$. Human colon adenocarcinoma $(\mathrm{CaCo}-2)$ cells were obtained from the European Collection of Animal Cell Cultures (ECACC; CAMR, Porton Down, UK). Cells were propagated in EMEM containing $10 \%(\mathrm{v} / \mathrm{v})$ fetal calf serum, $1 \%(\mathrm{v} / \mathrm{v})$ L-glutamine, $1 \%$ insulin-transferrin-selenium, $1 \%(\mathrm{v} / \mathrm{v})$ penicillin/streptomycin and $1 \%(\mathrm{v} / \mathrm{v})$ non-essential amino acids (Flow Laboratories). A confluent monolayer of CaCo-2 cells in an $8.0 \mathrm{~cm}^{2}$ flask was obtained within 5-7 days, with regular changes of medium. Cells were detached and cell suspensions prepared as described above.

Cytotoxicity assay. An assay based on toxin inhibition of the ability of active mitochondria in cultured mammalian cells to reduce a tetrazolium dye was used (Coote \& Arain, 1996). Each well of a flatbottomed, 24-well microtitre plate (Flow Laboratories) was loaded 
Table 1. Campylobacter jejuni isolates

Sources of isolation are indicated in the isolate code as follows: B, bovine; C, chicken; H, human; M, milk; O, ovine. Penner heat-stable serotypes (determined according to Owen et al., 1995) are indicated by the prefix 'HS'. 16S rDNA ribotypes (determined according to Fitzgerald et al., 1996) are indicated by the prefix ' $\mathrm{H}$ '.

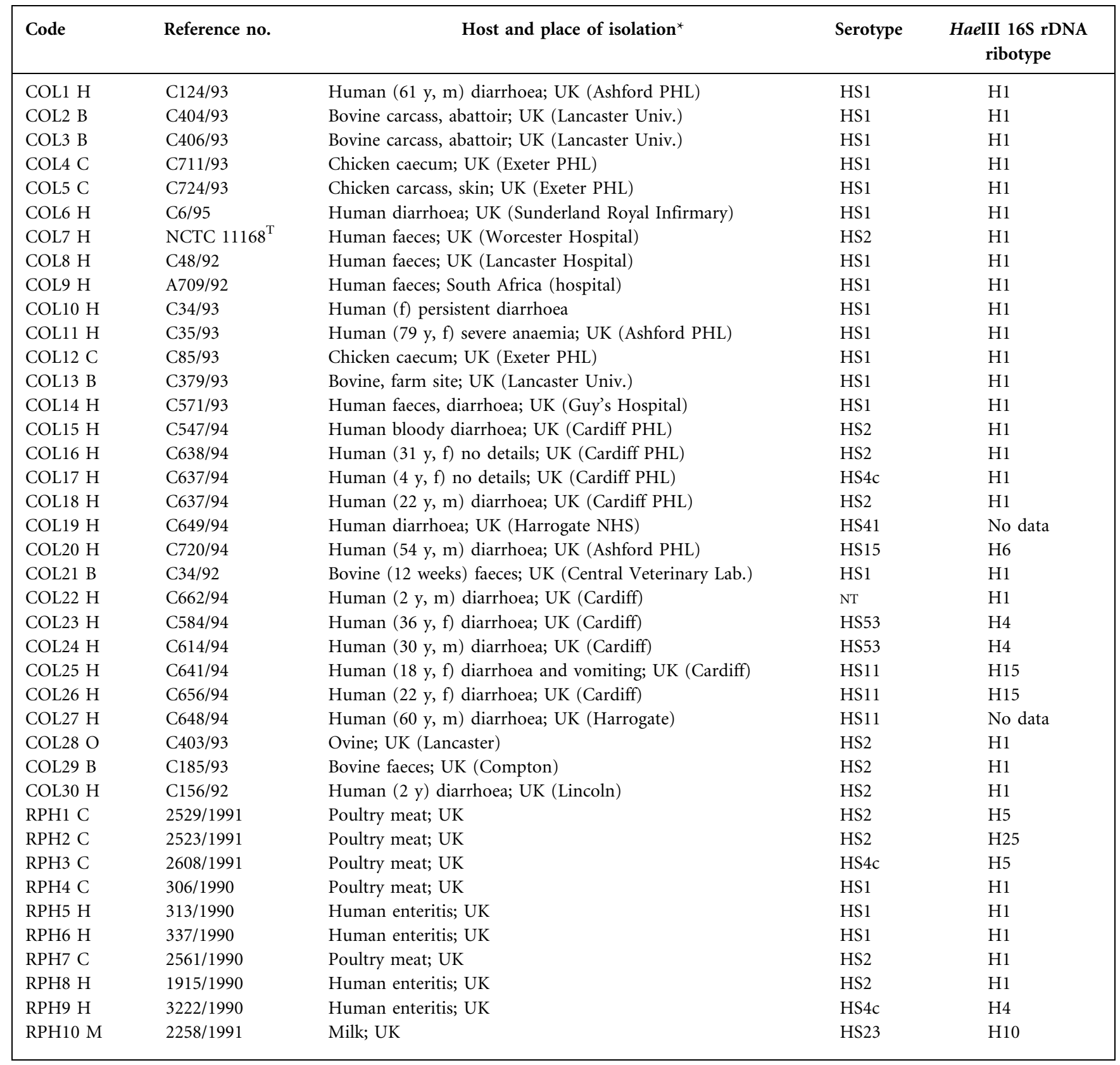

NT, Non-typeable.

${ }^{\star}$, Female; m, male; $y$, years of age; PHL, Public Health Laboratory.

with $200 \mu \mathrm{l}$ mammalian cell suspension and incubated at $37{ }^{\circ} \mathrm{C}$ overnight in an atmosphere of $5 \% \mathrm{CO}_{2}: 95 \%$ air (BOC) to allow the cells to adhere. A portion of the growth medium $(100 \mu \mathrm{l})$ was discarded and replaced with $100 \mu \mathrm{l}$ of a twofold dilution of the $C$. jejuni polymyxin B extract in E-MEM. Duplicate wells of each extract were set up: cells exposed to polymyxin B-treated Brucella broth and cells treated with $1 \%(\mathrm{v} / \mathrm{v})$ Triton X-100 served as negative (100\% live cells) and positive ( $0 \%$ live cells) controls, respectively. After $24 \mathrm{~h}$ incubation of the cell monolayers in the presence of bacterial cell extracts, $20 \mu \mathrm{l}$ of $0.5 \%(\mathrm{w} / \mathrm{v}) 3$-(4,5-dimethylthiazol-2-yl)-2,5-diphenyl tetrazolium bromide (MTT; Sigma) in PBS was added to each well and incubation was continued for a further $4 \mathrm{~h}$. The tetrazolium ring of MTT is cleaved by dehydrogenase activity to produce a dark-blue formazan product. The overlying medium was removed, the formazan product was solubilized by addition of $100 \mu \mathrm{l} 0.04 \mathrm{M}$ $\mathrm{HCl}$ in DMSO and the $A_{540}$ was measured in an Anthos 2001 
plate reader. Cytotoxicity (expressed as percentage cell death) was calculated by the formula:

$100 \times\left[1-\frac{A_{540}(\text { test })-A_{540}(\text { positive control })}{A_{540}(\text { negative control })-A_{540}(\text { positive control })}\right]$

\begin{abstract}
Adhesion and invasion assay. The $C$. jejuni isolates were grown in Brucella broth, as described above, harvested and washed once with sterile Dulbecco A PBS (10 mM, pH 7.3; Oxoid) and resuspended in E-MEM containing $10 \%(\mathrm{v} / \mathrm{v})$ fetal calf serum and $2 \mathrm{mM} \mathrm{L-}$ glutamine and adjusted to $1 \times 10^{9}$ cells $\mathrm{ml}^{-1}$. Mammalian cell monolayers (CaCo-2, HeLa or Vero) in 24-well tissue-culture plates were seeded at a concentration of $1 \times 10^{5}$ cells per well. After $24 \mathrm{~h}$, or when a monolayer of cells had formed, the growth medium was removed, the cell monolayer was washed twice with sterile warmed $\left(37^{\circ} \mathrm{C}\right) \mathrm{E}-\mathrm{MEM}$ and $1 \times 10^{9} \mathrm{C}$. jejuni cells in $1.0 \mathrm{ml} \mathrm{E}$-MEM were added per well in duplicate tests. Infected cell cultures were incubated at $37{ }^{\circ} \mathrm{C}$ for $3 \mathrm{~h}$ in an atmosphere of $5 \% \mathrm{CO}_{2} /$ air, after which the cell monolayers were washed five times with E-MEM to remove nonadherent bacteria, before the addition of either fresh E-MEM containing $100 \mu \mathrm{g}$ gentamicin $\mathrm{ml}^{-1}$ (Sigma) to measure invasive organisms alone or E-MEM alone for the estimation of adherent plus invasive organisms. After $2 \mathrm{~h}$ further incubation at $37^{\circ} \mathrm{C}$, all monolayers were washed five times with E-MEM and the bacteria were released by lysing the mammalian cells for 5 min with $1.0 \mathrm{ml}$ $1 \%(\mathrm{v} / \mathrm{v})$ Triton X-100 in PBS per well. Tenfold dilutions of the released bacteria were made in sterile water and viable counts were made on blood agar containing selective growth supplements. The number of c.f.u. of adherent cells alone was determined as c.f.u. of non-gentamicin culture (i.e. adherent + internalized c.f.u.) - c.f.u. of gentamicin-treated culture (i.e. internalized).
\end{abstract}

AFLP typing. AFLP genotyping was carried out according to Siemer et al. (2004, 2005). Briefly, genomic DNA prepared using Easy-DNA kit (Invitrogen) was simultaneously digested with a 'rare'- and a 'frequent'-cutting restriction enzyme and site-specific adapters were ligated onto the ends of the fragments. The fragments were amplified by PCR in which the primer complementary to the 'rare' restriction site/adaptor sequence was fluorochrome-labelled. The PCR products were separated on an ABI 377 automated sequencer (Applied Biosystems) (Kokotovic \& On, 1999). Gel images were pre-processed by GENESCAN version 3.1 (Applied Biosystems). The restriction enzymes used were BglII and Csp6I (Siemer et al., 2004) and fragments of 50-400 bases were included in the data analysis. Numerical analysis of the AFLP patterns was achieved with the Dice similarity coefficient and the UPGMA clustering algorithm in Bionumerics version 2.5 (Applied Maths) (On \& Harrington, 2000).

Statistical analysis. Statistical analysis of the cytotoxicity, adhesion and invasion and AFLP results of the COL and RPH strains was done with Minitab 12 (Minitab Ltd) using the procedures of Wardlaw (2000). When the isolate codes were unblinded at the end of the laboratory experiments, COL 28 , an ovine isolate, and RPH 10, a milk isolate, were excluded from statistical analyses of the results and the AFLP dendrograms as these were single-source isolates. Statistical significance was defined as $P<0.05$.

\section{RESULTS}

\section{Haemolytic activity}

None of the cell-free broth-culture supernates had haemolytic activity against washed RRBCs in the microtitre plate assay. However, the $C$. jejuni cells possessed variable degrees of haemolytic activity against RRBCs (Table 2). The type strain, NCTC $11168^{\mathrm{T}}$ (=COL 7), possessed little haemolytic activity, but COL 15, 16, 25 and 28 and RPH 5 and 9 , all but one being human isolates, showed titres of 16 (Table 2). COL 15 and 16, indicated by AFLP analysis to be a matched pair of isolates from the same source outbreak in Cardiff (see below), had the same level of haemolytic activity and similar phenotypes for the other virulenceassociated factors (Table 2). The three non-haemolytic strains from a human source, COL 6, 23 and 27, were isolated from patients with diarrhoea (Table 1).

\section{Cytotoxic activity}

None of the cell-free $C$. jejuni culture supernates had cytotoxic activity in the MTT assay. Polymyxin B extracts of all isolates were tested for cytotoxic activity against CaCo-2, Vero and HeLa cells (Table 2). None of the assays caused $100 \%$ cytotoxicity of the test cells over the $24 \mathrm{~h}$ period, indicating that the toxin activity was weak. The data showed a wide variation in toxic activity among the $C$. jejuni isolates. The cell extracts caused death of $0-77 \%$ of CaCo- 2 cells and $0-88 \%$ of HeLa cells, but were in general less active against Vero cells $(0-33 \%$ death). When the values for each group were displayed as Minitab point plots with 'jitter' (Wardlaw, 2000), a range of activities from high to low values was seen for CaCo-2 cells, whereas activities against Vero cells and, to a lesser extent, HeLa cells were clustered in the lower range (Fig. 1a). For CaCo2 cells, there was no significant correlation between the isolate source and the level of cytotoxin production (Fig. 1b). Extracts from isolates COL 4-6, 8, 11-14, 22 and 23 showed good activity against all target cells, but cellspecific cytotoxic activity was apparent with other cell extracts. For example, COL 1 and 30 and RPH 3-9 were essentially inactive against both HeLa and Vero cells but showed high activity against $\mathrm{CaCo}-2$ cells. Conversely, $\mathrm{COL}$ 3,15 and 16 were inactive against $\mathrm{CaCo}-2$ cells, but active against HeLa or Vero cells. COL $7\left(=\right.$ NCTC $\left.11168^{\mathrm{T}}\right)$ had only slight activity against $\mathrm{CaCo}-2$ and Vero cells and was inactive against HeLa cells.

\section{Adherence and invasion}

Adherence by $C$. jejuni isolates varied between $10^{6.9}$ c.f.u $\mathrm{ml}^{-1}\left(0.8 \%\right.$ of input bacteria) for CaCo- 2 cells to $10^{2.85}$ c.f.u. $\mathrm{ml}^{-1}(0.0001 \%$ of input bacteria) for Vero cells (Table 2). Variation between strains was most pronounced with Vero and HeLa cells, but strains adhered to CaCo-2 cells at $0.01-0.8 \%$ of input bacteria (Table 2 ). Minitab point plots with 'jitter' showed a trend for the $C$. jejuni isolates to adhere more effectively to $\mathrm{CaCo}-2$ cells while exhibiting a generally lower and similar adherence pattern to HeLa and Vero cells (Fig. 2a). Apart from COL 8, 19 and 20, more adherence was generally obtained with CaCo-2 cells than with HeLa and Vero cells (Table 2). Similarly, the capacity for cell invasion was most pronounced with $\mathrm{CaCo}-2$ cells and significantly greater overall than the invasive capacity 
Table 2. Haemolytic titres, cytotoxic activity and adhesion and invasion assays for the C. jejuni isolates

Isolate codes are explained in Table 1. In the adhesion (Adh.) assay, results are expressed as $\log _{10}$ c.f.u. $\mathrm{ml}^{-1}$ of adhered bacteria. For the invasion (Inv.) assay, the values represent the percentage of adherent organisms that invaded the cell lines. Both sets of data are the means of three duplicate tests. No organisms were detected in 12 controls inoculated with killed bacteria.

\begin{tabular}{|c|c|c|c|c|c|c|c|c|c|c|}
\hline \multirow{2}{*}{$\begin{array}{l}\text { C. jejuni } \\
\text { isolate }\end{array}$} & \multirow{2}{*}{$\begin{array}{c}\text { Haemolysis } \\
\text { titre }\end{array}$} & \multicolumn{3}{|c|}{ Cytotoxicity (\% dead cells) } & \multicolumn{2}{|c|}{ CaCo-2 } & \multicolumn{2}{|c|}{ HeLa } & \multicolumn{2}{|c|}{ Vero } \\
\hline & & CaCo-2 & HeLa & Vero & Adh. & Inv. & Adh. & Inv. & Adh. & Inv. \\
\hline COL $1 \mathrm{H}$ & 2 & 77 & 4 & 5 & 5.61 & 2.3 & 3.93 & 3.6 & 5.69 & 0.2 \\
\hline COL 2 B & 2 & 23 & $\mathrm{G}^{*}$ & 14 & 5.59 & 0.8 & 3.78 & 15.5 & 4.96 & 0.1 \\
\hline COL 3 B & 2 & 0 & 27 & 17 & 5.77 & 2.3 & 4.10 & 5.2 & 4.59 & 4.1 \\
\hline $\mathrm{COL} 4 \mathrm{C}$ & 4 & 14 & 11 & 25 & 5.95 & 1.4 & 5.23 & 0.5 & 5.40 & 0.7 \\
\hline COL $5 \mathrm{C}$ & 1 & 21 & 45 & 10 & 5.59 & 2.7 & 3.18 & 19.3 & 4.88 & 3.9 \\
\hline $\mathrm{COL} 6 \mathrm{H}$ & 0 & 17 & 36 & 27 & 5.00 & 10.3 & 3.63 & 23.0 & 3.90 & 75.0 \\
\hline COL $7 \mathrm{H}$ & 1 & 2 & G & 3 & 5.04 & 3.4 & 4.73 & 0.7 & 4.85 & 10.4 \\
\hline COL $8 \mathrm{H}$ & 2 & 10 & 29 & 22 & 4.93 & 1.2 & 5.08 & 0.3 & 5.78 & 0.4 \\
\hline $\mathrm{COL} 9 \mathrm{H}$ & 2 & 11 & 0 & 18 & 5.79 & 0.3 & 4.04 & 1.9 & 3.30 & 1.9 \\
\hline COL $10 \mathrm{H}$ & 4 & 21 & 0 & 2 & 6.90 & 0.1 & 3.23 & 25.3 & 3.52 & 0.8 \\
\hline COL $11 \mathrm{H}$ & 2 & 8 & 15 & 14 & 4.76 & 0.9 & 3.20 & 0 & 4.36 & 41.3 \\
\hline COL 12 C & 4 & 52 & 47 & 7 & 5.65 & 0.3 & 4.00 & 3.5 & 4.93 & 6.2 \\
\hline COL 13 B & 2 & 26 & 77 & 15 & 4.93 & 2.6 & 3.80 & 5.7 & 4.48 & 17.6 \\
\hline COL $14 \mathrm{H}$ & 4 & 24 & 66 & 21 & 5.08 & 46.8 & 3.54 & 16.9 & 4.99 & 43.8 \\
\hline COL $15 \mathrm{H}$ & 16 & 0 & 35 & 18 & 4.96 & 3.1 & 3.97 & 0.8 & 4.57 & 13.5 \\
\hline COL $16 \mathrm{H}$ & 16 & G & G & 23 & 5.51 & 0.1 & 5.58 & 0.04 & 5.25 & 2.4 \\
\hline COL $17 \mathrm{H}$ & 4 & 61 & G & 33 & 5.50 & 0.4 & 5.18 & 0.02 & 4.70 & 3.6 \\
\hline COL $18 \mathrm{H}$ & 8 & 22 & 65 & 0 & 5.59 & 2.4 & 4.49 & 2.4 & 3.84 & 2.9 \\
\hline COL $19 \mathrm{H}$ & 1 & G & G & G & 4.08 & 78.4 & 5.60 & 0.7 & 4.15 & 17.9 \\
\hline COL $20 \mathrm{H}$ & 2 & G & G & 16 & 3.74 & 39.3 & 6.04 & 0.5 & 4.00 & 24.0 \\
\hline COL $21 \mathrm{~B}$ & 1 & 45 & 0 & 14 & 6.67 & 6.3 & 4.15 & 32.1 & 5.11 & 0.7 \\
\hline COL $22 \mathrm{H}$ & 1 & 15 & 50 & 11 & 5.14 & 44.6 & 4.83 & 4.2 & 4.92 & 2.0 \\
\hline COL $23 \mathrm{H}$ & 0 & 28 & 61 & 32 & 4.17 & 40.5 & 3.85 & 18.3 & 3.45 & 10.8 \\
\hline COL $24 \mathrm{H}$ & 1 & 25 & 25 & 6 & 5.08 & 96.6 & 5.18 & 1.2 & 4.60 & 2.0 \\
\hline COL $25 \mathrm{H}$ & 16 & 23 & 8 & 5 & 4.14 & 12.1 & 3.53 & 58.8 & 3.58 & 8.4 \\
\hline COL $26 \mathrm{H}$ & 1 & 59 & 0 & 15 & 4.63 & 32.6 & 3.51 & 25.9 & 3.30 & 22.5 \\
\hline COL $27 \mathrm{H}$ & 0 & 40 & 0 & 8 & 4.59 & 17.5 & 4.04 & 10.9 & 3.26 & 20.0 \\
\hline COL $28 \mathrm{O}$ & 16 & 46 & 10 & 26 & 4.79 & 12.3 & 4.15 & 4.4 & 3.30 & 10.0 \\
\hline COL 29 B & 1 & 58 & 13 & 3 & 4.93 & 7.4 & 3.86 & 4.8 & 3.79 & 7.8 \\
\hline COL $30 \mathrm{H}$ & 1 & 62 & G & 5 & 4.30 & 16.0 & 3.45 & 64.3 & 2.85 & 35.5 \\
\hline $\mathrm{RPH} 1 \mathrm{C}$ & 1 & 38 & 19 & 4 & 4.77 & 73.9 & 3.30 & 24.0 & 4.88 & 2.3 \\
\hline RPH $2 \mathrm{C}$ & 4 & 30 & 13 & G & 5.93 & 4.1 & 3.26 & 12.8 & 5.04 & 5.9 \\
\hline RPH $3 \mathrm{C}$ & 2 & 47 & G & G & 4.64 & 24.8 & 3.30 & 26.7 & 4.65 & 1.9 \\
\hline $\mathrm{RPH} 4 \mathrm{C}$ & 1 & 50 & G & G & 5.75 & 8.4 & 3.96 & 1.3 & 5.78 & 0.13 \\
\hline RPH $5 \mathrm{H}$ & 16 & 47 & 7 & G & 5.97 & 5.0 & 4.74 & 1.4 & 4.65 & 1.5 \\
\hline $\mathrm{RPH} 6 \mathrm{H}$ & 4 & 28 & G & G & 6.38 & 7.5 & 4.86 & 0.5 & 4.38 & 9.6 \\
\hline RPH 7 C & 0 & 32 & G & G & 6.46 & 0.2 & 4.78 & 0.5 & 5.43 & 0.8 \\
\hline $\mathrm{RPH} 8 \mathrm{H}$ & 2 & 30 & G & 6 & 6.87 & 6.8 & 4.97 & 1.0 & 4.62 & 3.2 \\
\hline $\mathrm{RPH} 9 \mathrm{H}$ & 16 & 52 & G & G & 5.69 & 32.7 & 3.49 & 14.8 & 5.30 & 1.1 \\
\hline RPH $10 \mathrm{M}$ & 0 & 20 & 14 & G & 5.20 & 0.9 & 4.08 & 1.6 & 5.78 & 1.1 \\
\hline
\end{tabular}

${ }^{*} \mathrm{G}$, An increase in growth of cells was noted.

exhibited towards HeLa and Vero cells $(P<0.0001)$ (Fig. 2a). Nevertheless, although, for example, isolates COL 19 and 24 and RPH 1 had a considerably greater capacity to invade CaCo-2 cells compared with both HeLa and Vero cells, conversely, isolates COL 6, 25 and 30 had a greater capacity to invade either HeLa or Vero cells compared with
CaCo-2 cells (Table 2). There was no significant correlation between source of an isolate and the level of adhesion or invasion in CaCo-2 cells (Fig. 2b). Tukey's pairwise comparisons indicated no significant differences between human, bovine or chicken isolates for adherence or invasion of any of the cell lines. 

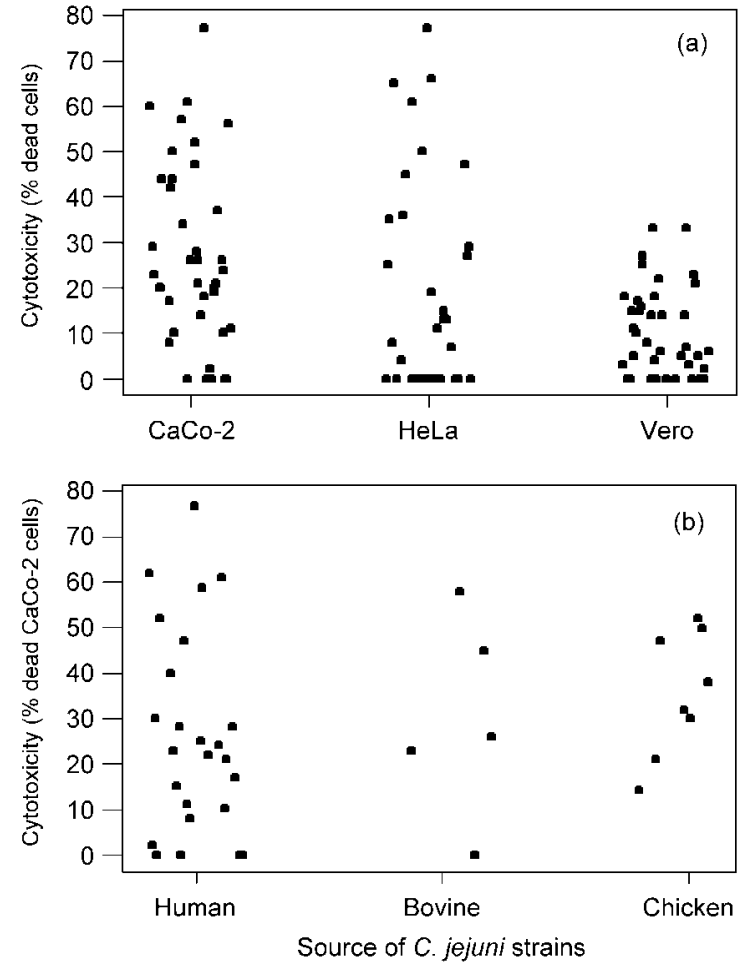

Fig. 1. Cytotoxic activity of C. jejuni isolates. (a) Values obtained from polymyxin extracts of individual isolates (Table 2) against CaCo-2, HeLa and Vero cells. (b) Values obtained against CaCo2 cells for isolates from different sources. Point plots of individual values were separated by 'jitter' of 0.1 .

\section{AFLP fingerprinting}

The C. jejuni isolates were all typeable by the AFLP protocol. The repeatability among independent duplicate profiles was tested $(n=34)$ and the mean similarity $(S)$ was $99.3 \%$ ( $\mathrm{SD} 1.2 \% \mathrm{~S}$ ). A dendrogram based on profiles is shown in Fig. 3. Five clusters (I-V, comprising 31 isolates) each representing two to eleven isolates with similar profiles were observed at the $90 \% \mathrm{~S}$ level. The remaining seven isolates displayed clearly distinct profiles. Within the five clusters, eight groups of two to four isolates had identical profiles, as indicated by the vertical terminal lines in the dendrogram. COL 28, the ovine isolate, was in cluster III and RPH10, the milk isolate, had a distinct profile (data not shown).

A conservative evaluation of the dendrogram results showed that six pairs of isolates (COL 2 and 3; COL 4 and 5; COL 10 and 11; COL 12 and 14; COL 15 and 16; and COL 13 and RPH 6) were identical. Profile similarity between isolates suggested that the following five groups of isolates may be clonally related: (i) COL 2, 3, 13 and 22 and RPH 6; (ii) COL 7 and 29; (iii) COL 10-12 and 14 and RPH 4 and 5; (iv) COL 15, 16 and 30; and (v) COL 25-27.

Group IV contained only strains isolated from a human source and groups I and V contained isolates from only
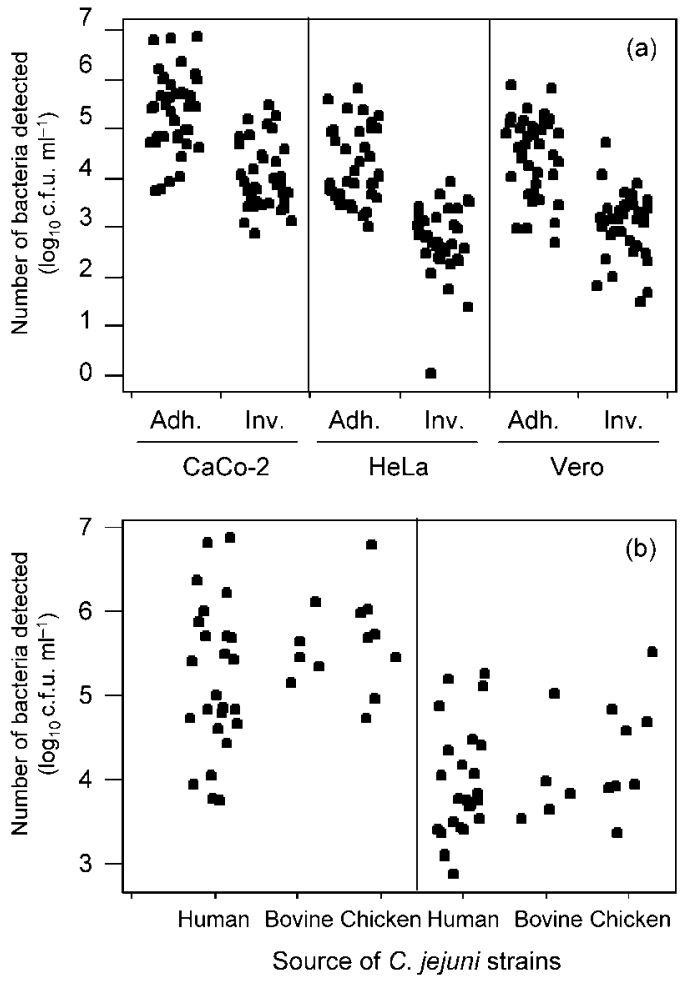

Fig. 2. Adhesion (Adh.) and invasion (Inv.) of the C. jejuni isolates. (a) Values obtained for individual isolates (Table 2) are shown for CaCo-2, HeLa and Vero cells. (b) Values obtained for adhesion (left panel) and invasion (right panel) with $\mathrm{CaCO}-2$ cells for isolates from different sources. Point plots of individual values were separated by 'jitter' of 0.025 .

two sources, human and chicken (Fig. 4). Group II contained isolates from only human and bovine sources, whereas group III, which contained the reference strain NCTC $11168^{\mathrm{T}}$ (=COL 7), contained isolates from all three sources, although they were mainly human isolates (Fig. 4). Although there was some clustering according to source, the numbers of isolates in some groups were small. Some isolates for which the typing had indicated identity were from the same source, COL 2 and 3 (bovine), COL 4 and 5 (chicken), COL 10 and 11 (human), COL 15 and 16 (human) and COL 25 and 26 (human), but two sets which had identical AFLP patterns ( $100 \%$ similarity) were from different sources: COL 12 (chicken) and COL 14 (human) and COL 13 (bovine) and RPH 6 (human) (Table 1 and Fig. 3), implicating chicken and cattle as potential sources of sporadic human infection.

\section{AFLP and concordance with other typing information}

Penner serotype and $16 \mathrm{~S}$ ribotype information were available for almost all the isolates (Table 1). The serotype and ribotype were the same for all pairs of identical isolates characterized by the AFLP protocol. Furthermore, ribotype 


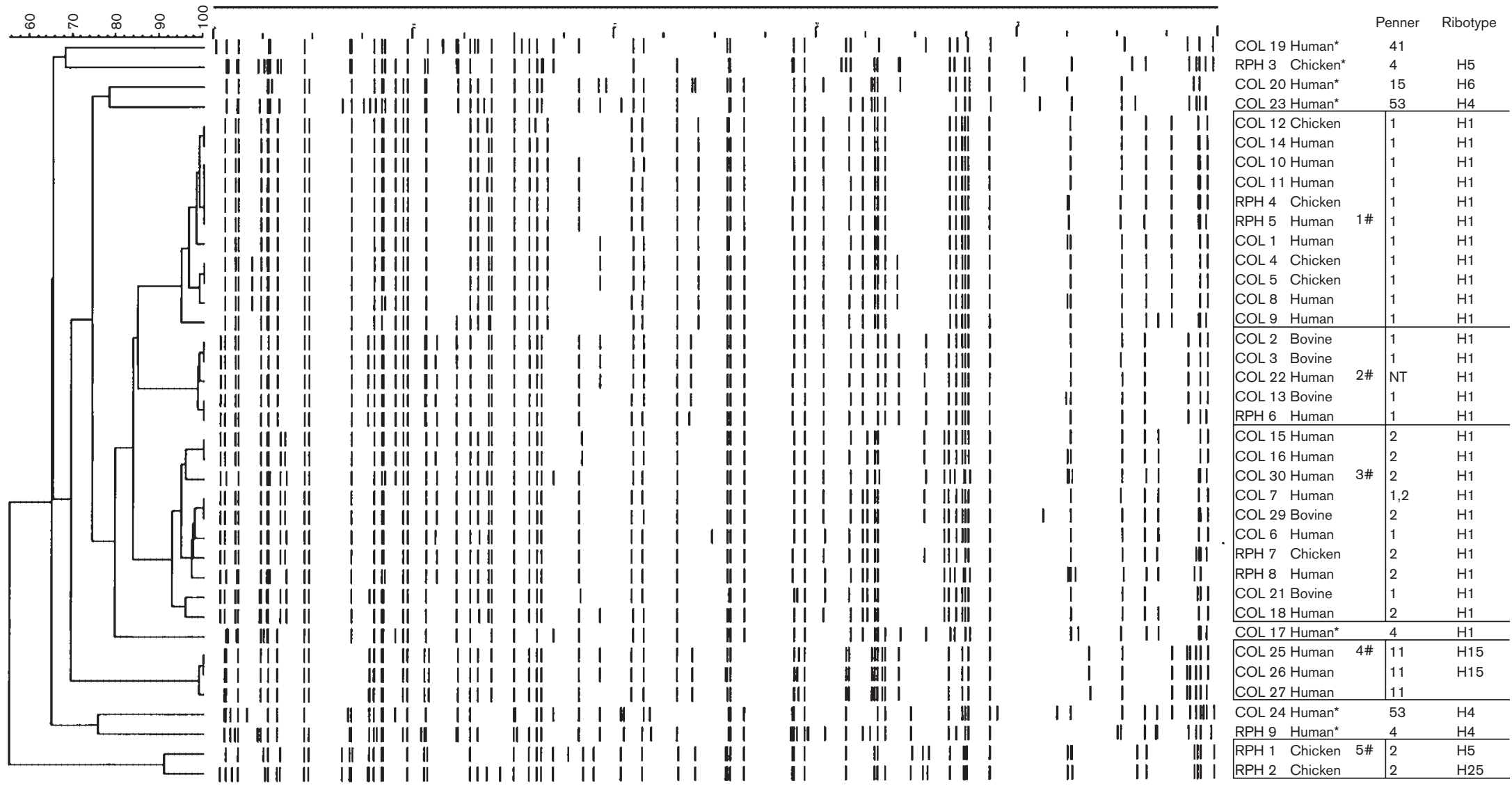

Fig. 3. AFLP groupings of the C. jejuni isolates (Siemer et al., 2004). Clusters (indicated as e.g. 1\#) were defined at $90 \%$ similarity. Asterisks indicate strains that were not grouped into clusters. 


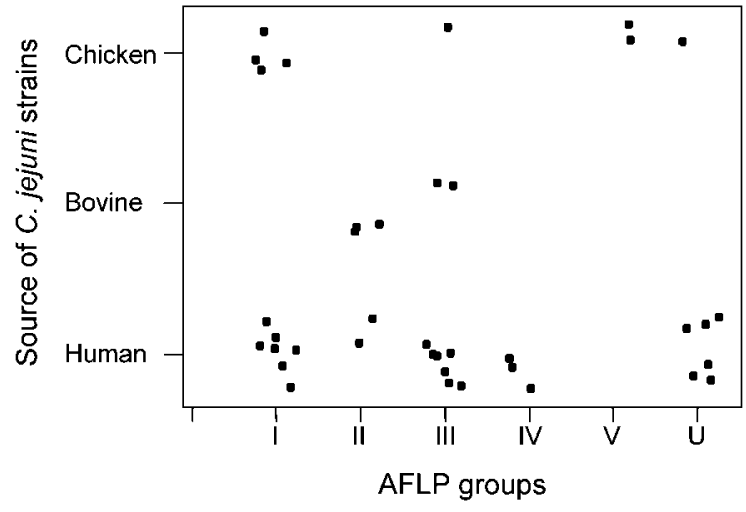

Fig. 4. C. jejuni isolates classified by source of isolation and AFLP groups. U, Unrelated. Point plots of individual values were separated by 'jitter' of 0.025 on both axes.

H1 was largely equivalent to clusters I, II and III, which comprised all serotype 1 and all but two of the serotype 2 strains which constituted cluster V (Fig. 3). The serotype and ribotype information also lends support to the suggested clonal relationships between isolates.

\section{Virulence-associated properties within AFLP clusters}

There was no significant correlation between possession of high haemolytic, cytotoxic or invasive activities of the isolates with particular genotypic clusters. A comparison of Minitab point plots with 'jitter' for the cytotoxicity and invasive properties of isolates showed that each AFLP group contained strains with a range of cytotoxic and invasive phenotypes against CaCo-2 cells (Fig. 5a, b). However, although only five isolates were grouped in AFLP group II, all exhibited low toxicity towards $\mathrm{CaCo}-2$ cells (Fig. 5a), and four of these, COL 2, 3 and 13 and RPH 6, had both low cytotoxic and invasive capacities against CaCo-2 cells (Table 2).

\section{DISCUSSION}

In agreement with other reports (Pickett et al., 1992; Hossain et al., 1993; Misawa et al., 1995a; Tay et al., 1995), whole cells of several of the isolates examined here were weakly haemolytic. Parkhill et al. (2000) reported that the genome of NCTC $11168^{\mathrm{T}}$ contained coding regions for putative contact-dependent haemolysins. The haemolysis assay used here was not designed specifically to detect contact haemolysis, and NCTC $11168^{\mathrm{T}}(=\mathrm{COL} 7)$ possessed little haemolytic activity under our assay conditions. For those strains exhibiting the highest haemolytic titres, COL 15, 16, 25 and 28 and RPH 5 and 9 , it was not possible to attribute this activity clearly to cytotoxicity measured against $\mathrm{CaCo}-2$, Vero or HeLa cells (Table 2). Thus, although four of the six isolates (COL 25
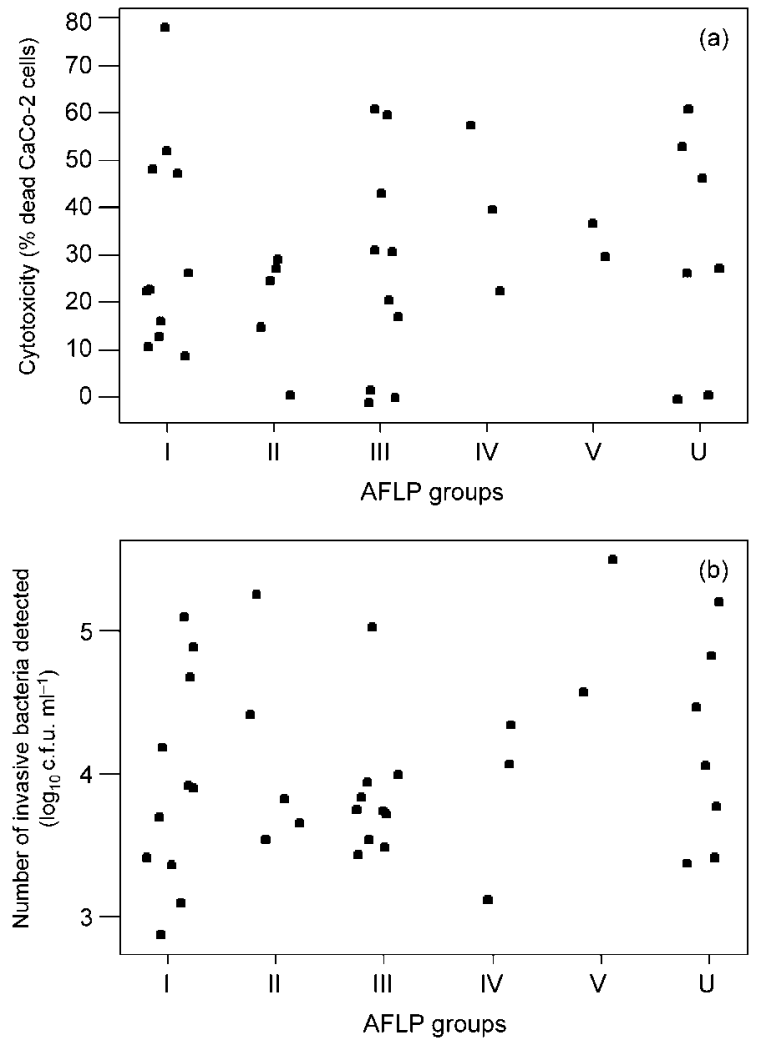

Fig. 5. Cytotoxic (a) and invasive (b) activities against $\mathrm{CaCo}-2$ cells of $C$. jejuni isolates within AFLP groups. U, Unrelated. Point plots of individual values were separated by 'jitter' of 0.05 .

and 28 and RPH 5 and 9) had quite marked cytotoxic activity against $\mathrm{CaCo}-2$ cells, COL 15 and 16 did not and were only marginally more active against HeLa or Vero cells. Conversely, some isolates that possessed high cytotoxic activity against $\mathrm{CaCo}-2$ cells, such as COL 1, 17, 29 and 30, had very low haemolytic titres. These data would thus suggest that the haemolytic and cytotoxic activities detected were due to separate factors.

A range of cytotoxic activities was exhibited by the strains, with some having no activity against any of the target cells. Of particular note was the very low cytotoxicity exhibited by the type strain NCTC $11168^{\mathrm{T}}$. This is at variance with a previous study (Coote \& Arain, 1996), which demonstrated cytotoxicity of NCTC $11168^{\mathrm{T}}$ against HeLa and Vero cells. The reason for this discrepancy is unclear, but the strain NCTC $11168^{\mathrm{T}}$ was obtained from different sources in the two studies and the assays, although similar, differed in procedure. In this study, some strains showed activity against all three target cells, whereas there was obvious isolate variation with others in the ability to produce cytotoxic activity against the three target cell lines when they were grown and assayed under identical conditions. Thus, certain strains showed good activity against $\mathrm{CaCo}-2$ cells and little or no activity against the other cell lines, while other isolates exhibited the opposite phenotype 
(Table 2). These data suggest that the assays using the different cell lines may have detected more than one cytotoxin, as noted previously (Wassenaar, 1997; Pickett, 2000). Overall, the results corroborate previous reports where low-level cytotoxicity was reported against $\mathrm{CHO}$ (Chinese hamster ovary), HeLa, Vero, J774 (mouse macrophage-like) and Int 407 (human intestinal epithelial) cells, but variation in cytotoxic activity between $C$. jejuni strains was noted (Guerrant et al., 1987; Pang et al., 1987; Moore et al., 1988; Misawa et al., 1995b; Lee et al., 2000; Nadeau et al., 2003). This report extends these observations to include $\mathrm{CaCo}-2$ cells, proposed as a more suitable target cell for C. jejuni (Everest et al., 1992), and provides a more quantitative assay than those used in previous work, which, with the exception of Nadeau et al. (2003), who also used the dye-reduction assay described here, relied on cytopathic changes to cultured mammalian cells that required prolonged incubation periods and provided only semiquantitative data. Statistical analysis showed that, as a group of 38 isolates, the source showed no statistical significance with regard to cytotoxic capacity. For example, within the human isolates, cytotoxic activities varied between 0 and $77 \%$ for CaCo-2, 0 and $33 \%$ for Vero and 0 and $66 \%$ for HeLa cells. A similar range of activities was found with bovine and chicken isolates. Other workers noted no significant difference in the extent of cytotoxin activity between human and animal isolates (Misawa et al., 1995b; Nadeau et al., 2003), although Lee et al. (2000), in a study of ten strains from human or chicken sources, found cytotoxin producers to be mainly human isolates.

It is unlikely that the cytotoxic activity described here can be attributed to cytolethal distending toxin (CDT). This toxin has been shown to interfere with cell-cycle progression in certain mammalian cells, including HeLa, $\mathrm{CHO}$ and CaCo-2 cells, by promoting DNA damage, but cell death occurs after more than $48 \mathrm{~h}$ exposure to the toxin (Pickett, 2000; Lara-Tejero \& Galan, 2002). A CDT-deficient mutant of C. jejuni 81-176 still elicited cytopathic effects on HeLa, Vero and CaCo-2 cells (Purdy et al., 2000; A. Mohammadzadeh, R. Parton and J. G. Coote, unpublished observations). Purdy et al. (2000) also reported that a CDTdeficient mutant of $C$. jejuni NCTC $11168^{\mathrm{T}}$ did not have any residual cytotoxic activity against HeLa or Int 407 cells, which is in agreement with results reported here, where the type strain NCTC $11168^{\mathrm{T}}$ (=COL 7) exhibited little cytotoxic activity against $\mathrm{HeLa}$ and $\mathrm{CaCo}-2$ cells. In addition, the low activity shown by strain NCTC $11168^{\mathrm{T}}$ (=COL 7) against Vero cells (Table 2) was not reduced further by mutants deficient in the putative haemolysin tly $A$ (Cj05888) or phospholipase pldA (Cj0183) (A. Mohammadzadeh, R. Parton and J. G. Coote, unpublished observations; mutants kindly supplied by P. Everest, Veterinary College, Glasgow University).

As with cytotoxic activity, a wide variation between individual isolates was obtained for both adherence and invasion with all cell lines (Table 2). Overall, the strains showed greater adherence and significantly greater invasion capacities with human colonic $\mathrm{CaCo}-2$ cells than with human epithelial HeLa or monkey kidney Vero cells. Thus, although the relevance of in vitro studies to the behaviour of bacteria in vivo is open to question, this demonstrates the importance of an in vitro cell culture model for epithelial cell adhesion and invasion that resembles more closely the cell type that campylobacters interact with in vivo. Previous work using CaCo-2 cells indicated that more invasive strains may correspond to those that cause colitis and more severe disease symptoms (Everest et al., 1992). Studies with infant rhesus monkeys showed that the primary mechanism of colitis by strain $81-176$ was associated with invasion of the bacteria into the absorptive epithelial cells in the colon (Russell et al., 1993).

Cytotoxicity, adherence and invasion may be responsible, individually or in combination, for the manifestations of $C$. jejuni-induced enteritis, including diarrhoea and inflammation. In some cases, a correlation between cytotoxic activity and the capacity to invade cells was evident. Thus, COL 14, 23, 26, 27 and 30 and RPH 1, 3 and 9 showed high cytotoxic and invasive activities against $\mathrm{CaCo}-2$ cells (Table 2). All these COL isolates and RPH 9 were from human cases of diarrhoea or enteritis, but RPH 1 and 3 were poultry isolates. With other strains, for example COL $1,12,13,17,18,21$ and 29 and RPH 2 and 4-8, high cytotoxic activity was accompanied by a low invasive capacity for CaCo-2 cells. These strains were from human, chicken and bovine sources. For COL 19 and 20 (from human cases of diarrhoea), the converse was true, these strains exhibiting high invasive capacity and no detectable cytotoxicity for CaCo-2 cells (Table 2). For our isolates as a whole, there was no clear relationship between source of isolation or disease manifestation and possession of statistically significantly higher levels of particular virulence-associated factors assayed in these studies (Table 2, Figs $1 \mathrm{~b}$ and $2 \mathrm{~b}$ ).

Whole-genome AFLP detection is an effective tool for identifying genetic relatedness of $C$. jejuni isolates. Profiles clustering at similarity values $>90 \%$ have been shown to identify groups of strains with epidemiological or clonal significance (On \& Harrington, 2000; Siemer et al., 2004). Five groups of strains were identified that clustered together at or just below this similarity value (Fig. 3). When the source of the isolates was compared with the AFLP clusters, it was clear that each group had C. jejuni isolates from more than one source, with the exception of group IV, which contained only human isolates (Fig. 4). The placement of strains in the AFLP groups may provide an indication of shared characteristics. Other studies have shown genetic relatedness between individual isolates from a single source, either human strains or strains from nonhuman reservoirs (On et al., 1998; Duim et al., 1999; Fitzgerald et al., 2001; Dingle et al., 2002; Schouls et al., 2003; Siemer et al., 2004). Our study also showed that four of the five groups contained strains of the same serotype (groups I and II, serotype 1; group IV, serotype 11; and group V, serotype 2). Group III contained isolates of serotypes 1 and 2 . This is similar to previous reports, where 
several AFLP clusters contained strains assigned to a single serotype (Desai et al., 2001; Siemer et al., 2004). The data confirm genetic heterogeneity of $C$. jejuni and support the existence of distinct groups or clusters, some of which contain isolates with a common serotype.

The relationship of the AFLP groups to the expression of virulence-associated factors can also be assessed. It was reported previously that highly $\mathrm{CHO}$ cell-cytotoxic isolates were distributed in two clusters identified by PFGE (Nadeau et al., 2003), but our data supported this to only a limited extent, as isolates having high cytotoxic activity against CaCo-2 cells were present in groups I, III, IV and a group of unrelated strains (U) identified by AFLP analysis (Fig. 5a). Group II isolates had uniformly low cytotoxicity. Similarly, in a recent report (On et al., 2006), CDT and haemolysin activities were not significantly different between two clusters of strains differentiated on the basis of wholegenome microarray analysis of interstrain gene polymorphism. However, the authors did detect a significant difference between the clusters with regard to survival under aerobic conditions, a phenotype which was not tested here. Assessment of the capacity of groups to invade $\mathrm{CaCo}-2$ cells indicated that isolates in groups $\mathrm{I}, \mathrm{V}$ and $\mathrm{U}$ had a noticeably greater capacity overall to invade the cells than isolates in groups II, III and IV (Fig. 5b). These differences in cytotoxic activity or invasive capacity did not, however, relate in any obvious way to source of isolation except that group IV, which contained isolates with higher cytotoxic and invasive capacities, contained isolates from human sources only. To some extent, these data support other reported work, where the potential for invasion was significantly higher for human than for poultry isolates (Nadeau et al., 2003). The phenotypic data, together with the genotypic AFLP analysis, emphasize the heterogeneity of C. jejuni isolates, and our data overall do not support the idea that clonally related isolates have common in vitro virulence characteristics. This is in keeping with other work that has shown genetic plasticity by whole-genome DNA comparisons (Wassenaar et al., 1998; Dorrell et al., 2001; Suerbaum et al., 2001; de Boer et al., 2002; Leonard et al., 2003; On et al., 2006) and single-nucleotide polymorphisms that arose between clonal variants of the type strain NCTC $11168^{\mathrm{T}}$ that resulted in differences in gene expression and the capacity to colonize chicks (Gaynor et al., 2004). There is a requirement to examine strains by in vivo methods to obtain a clearer picture of $C$. jejuni virulence.

\section{ACKNOWLEDGEMENTS}

D. E. S. S.-T. and J. G. C. wish to thank the UK Department of Health for a contract grant to support part of this work.

\section{REFERENCES}

Coote, J. G. \& Arain, T. (1996). A rapid, colourimetric assay for cytotoxin activity in Campylobacter jejuni. FEMS Immunol Med Microbiol 13, 65-70. de Boer, P., Wagenaar, J. A., Achterberg, R. P., van Putten, J. P. M., Schouls, L. M. \& Duim, B. (2002). Generation of Campylobacter jejuni genetic diversity in vivo. Mol Microbiol 44, 351-359.

Desai, M., Logan, J. M. J., Frost, J. A. \& Stanley, J. (2001). Genome sequence-based fluorescent amplified fragment length polymorphism of Campylobacter jejuni, its relationship to serotyping and its implications for epidemiological analysis. J Clin Microbiol 39, 3823-3829.

Dingle, K. E., Colles, F. M., Ure, R., Wagenaar, J. A., Duim, B., Bolton, F. J., Fox, A. J., Wareing, D. R. A. \& Maiden, M. C. (2002). Molecular characterization of Campylobacter jejuni clones: a basis for epidemiologic investigation. Emerg Infect Dis 8, 949-955.

Dorrell, N., Mangan, J. A., Laing, K. G., Hinds, J., Linton, D., AlGhusein, H., Barrell, B. G., Parkhill, J., Stoker, N. G. \& other authors (2001). Whole genome comparison of Campylobacter jejuni human isolates using a low-cost microarray reveals extensive genetic diversity. Genome Res 11, 1706-1715.

Duim, B., Wassenaar, T. M., Rigter, A. \& Wagenaar, J. (1999). Highresolution genotyping of Campylobacter strains isolated from poultry and humans with amplified fragment length polymorphism fingerprinting. Appl Environ Microbiol 65, 2369-2375.

Everest, P. H., Goosens, H., Butzler, J. P., Lloyd, D., Knutton, S., Ketley, J. M. \& Williams, P. H. (1992). Differentiated Caco-2 cells as a model for enteric invasion by Campylobacter jejuni and C. coli. J Med Microbiol 37, 319-325.

Everest, P. H., Cole, A. T., Hawkey, C. J., Knutton, S., Goosens, H., Butzler, J. P., Ketley, J. M. \& Williams, P. H. (1993). Roles of leukotriene B4, prostaglandin E2 and cyclic AMP in Campylobacter jejuni-induced intestinal fluid secretion. Infect Immun 61, 4885-4887.

Fitzgerald, C., Owen, R. J. \& Stanley, J. (1996). Comprehensive ribotyping scheme for heat-stable serotypes of Campylobacter jejuni. J Clin Microbiol 34, 265-269.

Fitzgerald, C., Stanley, J., Andrew, S. \& Jones, K. (2001). Use of pulse-field gel electrophoresis and flagellin gene typing in identifying clonal groups of Campylobacter jejuni and Campylobacter coli in farm and clinical environments. Appl Environ Microbiol 67, 1429-1436.

Gaynor, E. C., Cawthraw, S., Manning, G., MacKichan, J. K., Falkow, S. \& Newell, D. G. (2004). The genome-sequenced variant of Campylobacter jejuni NCTC 11168 and the original clonal clinical isolate differ markedly in colonization, gene expression, and virulenceassociated phenotypes. J Bacteriol 186, 503-517.

Griffiths, P. L. \& Park, R. W. A. (1990). Campylobacters associated with human diarrhoeal disease. J Appl Bacteriol 69, 281-301.

Guerrant, R. L., Wanke, C. A., Pennie, R. A., Barrett, L. J., Lima, A. A. M. \& O'Brien, A. D. (1987). Production of a unique cytotoxin by Campylobacter jejuni. Infect Immun 55, 2526-2530.

Hickey, T. E., Baqar, S., Bourgeois, A. L., Ewing, C. P. \& Guerry, P. (1999). Campylobacter jejuni stimulated secretion of interleukin-8 by INT407 cells. Infect Immun 67, 88-93.

Hossain, A., Stewart-Tull, D. E. S. \& Freer, J. H. (1993). Heat-labile and heat-stable haemolysins of Campylobacter jejuni. FEMS Immunol Med Microbiol 6, 331-340.

Ketley, J. M. (1997). Pathogenesis of enteric infection by Campylobacter. Microbiology 143, 5-21.

Kokotovic, B. \& On, S. L. W. (1999). High-resolution genomic fingerprinting of Campylobacter jejuni and Campylobacter coli by analysis of amplified fragment length polymorphisms. FEMS Microbiol Lett 173, 77-84.

Konkel, M. E. \& Joens, L. A. (1989). Adhesion to and invasion of HEp2 cells by Campylobacter spp. Infect Immun 57, 2984-2990. 
Konkel, M. E., Corwin, M. D., Joens, L. A. \& Cieplak, W. (1992). Factors that influence the interaction of Campylobacter jejuni with cultured mammalian cells. J Med Microbiol 37, 30-37.

Lara-Tejero, M. \& Galan, J. E. (2002). Cytolethal distending toxin: limited damage as a strategy to modulate cellular functions. Trends Microbiol 10, 147-152.

Lee, A., Smith, S. C. \& Coloe, P. J. (2000). Detection of a novel campylobacter cytotoxin. J Appl Microbiol 89, 719-725.

Leonard, E. E., Takata, T., Blaser, M. J., Falkow, S., Tompkins, L. S. \& Gaynor, E. C. (2003). Use of an open-reading frame-specific Campylobacter jejuni DNA microarray as a new genotyping tool for studying epidemiologically related isolates. J Infect Dis 187, 691-694.

MacCallum, A., Haddock, G. \& Everest, P. H. (2005). Campylobacter jejuni activates mitogen-activated protein kinases in Caco-2 cell monolayers and in vitro infected primary human colonic tissue. Microbiology 151, 2765-2772.

Mellits, K. H., Mullen, J., Wand, M., Armbruster, G., Patel, A., Connerton, P. L., Skelly, M. \& Connerton, I. F. (2002). Activation of the transcription factor NF- $\kappa$ B by Campylobacter jejuni. Microbiology 148, 2753-2763.

Misawa, N., Hirayama, K., Itoh, K. \& Takahashi, E. (1995a). Detection of alpha- and beta-hemolytic-like activity from Campylobacter jejuni. J Clin Microbiol 33, 729-731.

Misawa, N., Ohnishi, T., Itoh, K. \& Takahashi, E. (1995b). Cytotoxin detection in Campylobacter jejuni strains of human and animal origin with three tissue culture systems. J Med Microbiol 43, 354-359.

Moore, M. A., Blaser, M. J., Perez-Perez, G. I. \& O’Brien, A. D. (1988). Production of a Shiga-like toxin by Campylobacter. Microb Pathog $\mathbf{4}$, 455-462.

Nadeau, E., Messier, S. \& Quessy, S. (2003). Comparison of Campylobacter isolates from poultry and humans: association between in vitro virulence properties, biotypes and pulse-field gel electrophoresis clusters. Appl Environ Microbiol 69, 6316-6320.

Oelschlaeger, T. A., Guerry, P. \& Kopecko, D. J. (1993). Unusual microtubule-dependent endocytosis mechanisms triggered by Campylobacter jejuni and Citrobacter freundii. Proc Natl Acad Sci U S A 90, 6884-6888.

On, S. L. W. \& Harrington, C. S. (2000). Identification of taxonomic and epidemiological relationships among Campylobacter species by numerical analysis of AFLP profiles. FEMS Microbiol Lett 193, 161-169.

On, S. L. W., Nielson, E. M., Engberg, J. \& Madsen, M. (1998). Validity of SmaI-defined genotypes of Campylobacter jejuni examined by SalI, $K p n \mathrm{I}$ and BamHI polymorphisms: evidence of identical clones infecting humans, poultry and cattle. Epidemiol Infect 120, 231-237.

On, S. L. W., Dorrell, N., Petersen, L., Bang, D. D., Morris, S., Forsythe, S. J. \& Wren, B. W. (2006). Numerical analysis of DNA microarray data of Campylobacter jejuni strains correlated with survival, cytolethal distending toxin and haemolysin analyses. Int $J$ Med Microbiol 296, 353-363.

Owen, R. J., Sutherland, K., Fitzgerald, C., Gibson, J., Borman, P. \& Stanley, J. (1995). Molecular subtyping scheme for serotypes HS1 and HS4 of Campylobacter jejuni. J Clin Microbiol 33, 872-877.

Pang, T., Wong, P. Y., Puthucheary, S. D., Sihotang, K. \& Chang, W. K. (1987). In-vitro and in-vivo studies of a cytotoxin from Campylobacter jejuni. J Med Microbiol 23, 193-198.
Parkhill, J., Wren, B. W., Mungall, K., Ketley, J. M., Churcher, C., Basham, D., Chillingworth, T., Davies, R. M., Feltwell, T. \& other authors (2000). The genome sequence of the food-borne pathogen Campylobacter jejuni reveals hypervariable sequences. Nature 403, 665-668.

Penner, J. L. \& Hennessy, J. N. (1980). Passive hemagglutination technique for serotyping Campylobacter fetus subsp jejuni on the basis of soluble heat-stable antigens. J Clin Microbiol 12, 732-737.

Pickett, C. L. (2000). Campylobacter toxins and their role in pathogenesis. In Campylobacter, 2nd edn, pp. 179-190. Edited by I. Nachamkin \& M. J. Blaser. Washington DC: American Society for Microbiology.

Pickett, C. L., Auffenberg, T., Pesci, E. C., Sheen, V. L. \& Jusef, S. S. D. (1992). Iron acquisition and hemolysin production by Campylobacter jejuni. Infect Immun 60, 3872-3877.

Purdy, D., Buswell, C. M., Hodgson, A. E., McAlpine, K., Henderson, I. \& Leach, S. A. (2000). Characterisation of cytolethal distending toxin (CDT) mutants of Campylobacter jejuni. J Med Microbiol 49, 473-479.

Russell, R. G., O’Donnoghue, M., Blake, D. C., Jr, Zulty, J. \& DeTolla, L. J. (1993). Early colonic damage and invasion of Campylobacter jejuni in experimentally challenged infant Macaca mulatta. J Infect Dis 168, 210-215.

Schouls, L. M., Reulen, S., Duim, B., Wagenaar, J. A., Willems, R. J. L., Dingle, K. E., Colles, F. M. \& Van Embden, J. D. A. (2003). Comparative genotyping of Campylobacter jejuni by amplified fragment length polymorphism, multilocus sequence typing and short repeat sequencing: strain diversity, host range and recombination. J Clin Microbiol 41, 15-26.

Siemer, B. L., Harrington, C. S., Nielsen, E. M., Borck, B., Nielsen, N. L., Engberg, J. \& On, S. L. W. (2004). Genetic relatedness among Campylobacter jejuni serotyped isolates of diverse origin as determined by numerical analysis of amplified fragment length polymorphism (AFLP) profiles. J Appl Microbiol 96, 795-802.

Siemer, B. L., Nielsen, E. M. \& On, S. L. W. (2005). Identification and molecular epidemiology of Campylobacter coli isolates from human gastroenteritis, food, and animal sources by amplified fragment length polymorphism analysis and Penner serotyping. Appl Environ Microbiol 71, 1953-1958.

Suerbaum, S., Lohrengel, M., Sonnevend, A., Ruberg, F. \& Kist, M. (2001). Allelic diversity and recombination in Campylobacter jejuni. J Bacteriol 183, 2553-2559.

Tay, S. T., Devi, S., Puthucheary, S. \& Kautner, I. M. (1995). Detection of haemolytic activity of campylobacters by agarose haemolysis and microplate assay. J Med Microbiol 42, 175-180.

Ullmann, U. (1979). Methods in Campylobacter. Methods Microbiol 13, 435-452.

Wardlaw, A. C. (2000). Practical Statistics for Experimental Biologists, 2nd edn. Chichester: Wiley.

Wassenaar, T. M. (1997). Toxin production by Campylobacter spp. Clin Microbiol Rev 10, 466-476.

Wassenaar, T. M. \& Blaser, M. J. (1999). Pathophysiology of Campylobacter jejuni infections of humans. Microbes Infect 1, 10231033.

Wassenaar, T. M., Geilhausen, B. \& Newell, D. G. (1998). Evidence of genomic instability in Campylobacter jejuni isolated from poultry. Appl Environ Microbiol 64, 1816-1821. 